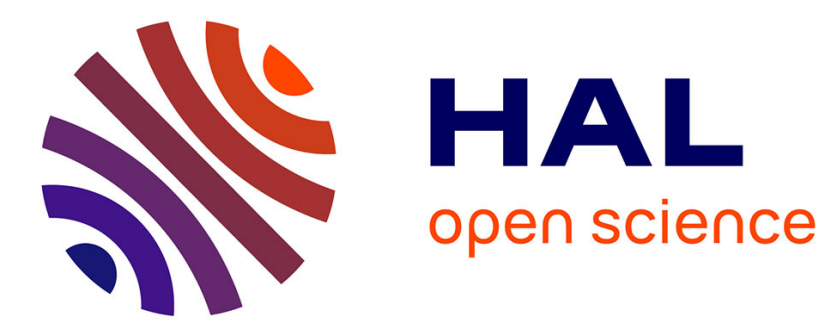

\title{
Prevalence of Chlamydia trachomatis: results from the first national population-based survey in France
}

\author{
Véronique Goulet, Bertille de Barbeyrac, Sophie Raherison, Muriel
}

Prudhomme, Caroline Semaille, Josiane Warszawski

\section{To cite this version:}

Véronique Goulet, Bertille de Barbeyrac, Sophie Raherison, Muriel Prudhomme, Caroline Semaille, et al.. Prevalence of Chlamydia trachomatis: results from the first national population-based survey in France. Sexually Transmitted Infections, 2010, 86 (4), pp.263. 10.1136/sti.2009.038752 . hal00557458

\section{HAL Id: hal-00557458 \\ https://hal.science/hal-00557458}

Submitted on 19 Jan 2011

HAL is a multi-disciplinary open access archive for the deposit and dissemination of scientific research documents, whether they are published or not. The documents may come from teaching and research institutions in France or abroad, or from public or private research centers.
L'archive ouverte pluridisciplinaire HAL, est destinée au dépôt et à la diffusion de documents scientifiques de niveau recherche, publiés ou non, émanant des établissements d'enseignement et de recherche français ou étrangers, des laboratoires publics ou privés. 
Title :

Prevalence of Chlamydia trachomatis: results from the first national population-based survey in France

Authors: V Goulet, B de Barbeyrac, S. Raherison, M Prudhomme, C. Semaille, J Warszawski; CSF group

Corresponding author:

Véronique Goulet ; Institut de Veille Sanitaire, 12 rue du val d'Osne, 94410 Saint-Maurice, France v.goulet@invs.sante.fr

Tel : 33141796723 Fax : 33141796769

Co-authors :

Bertille de Barbeyrac, National Reference Centre for Chlamydia, University of Bordeaux 2, Bordeaux, France

Sophie Raherison, National Reference Centre for Chlamydia, University of Bordeaux 2, France

Muriel Prudhomme, Conseil Général, Saint-Denis, France

Caroline Semaille, Institut de Veille Sanitaire, Saint-Maurice, France

Josiane Warszawski, Inserm Unité 569, Le Kremlin Bicêtre, France

CSF group : Nathalie Bajos, M. Bozon, N. Beltzer, A. Andro, M. Ferrand, V. Goulet, A. Laporte, Ch. Le Van, H. Leridon, Sh. Levinson, N. Razafindratsima, L.Toulemon, J. Warszawski , Inserm-Ined Unité 569, Le Kremlin Bicêtre, France

Key-words : Chlamydia trachomatis, prevalence, population-based

Word count: 3034 
Abstract

Objectives: Few studies have estimated Chlamydia trachomatis (CT) prevalence in the general population, most prevalence studies being based on people already attending healthcare settings. We estimated the prevalence of CT in France, assessed the feasibility of home sampling without any faceto-face intervention, and identified risk factors associated with CT infection using data from the Contexte de la Sexualité (CSF) survey on sexual behaviour.

Methods: CSF was a national population-based survey, carried out by telephone in 2006. A random subsample of sexually experienced individuals aged 18-44 ( $N=4957)$ were invited to participate in a CT home-sampling study (NatChla Study). Participants were tested for CT by PCR. Percentages were weighted for unequal selection probabilities and post-stratified based on French population census data. Independent risk factors were identified by logistic regression.

Results: CT prevalence in individuals aged 18-44 was estimated at $1.4 \%$ [95 \% Cl: 0.8- 2.6] for men, and $1.6 \%[95 \% \mathrm{Cl}: 1.0-2.5]$ for women. We observed increased rates in individuals aged 18-29: $2.5 \%$ [95\%Cl:1.2-5.0] for men and $3.2 \%$ [95\% Cl:2.0 -5.3] for women. CT infection was associated, for both genders, with having their last sexual intercourse with a casual or new partner. Other risk factors were for men, living in the Paris area, and for women, multiple partners during the previous year, same sex partners and a low level of education.

Conclusions: CT prevalence in France is similar to other developed countries. Home-sampling proved feasible and useful to reach members of the population with limited access to traditional care. 


\section{Introduction}

Chlamydia trachomatis (CT) infection is the most commonly reported bacterial sexually transmitted infection in industrialised countries. Most genital chlamydial infections are asymptomatic. This allows the infection to spread undetected, potentially leading to severe long-term complications in women's reproductive tracts(1). Such complications may be avoided by antibiotic therapy on early stage of the infection.

Systematic screening may reduce complications and the transmission of CT in the population (2). However, the cost-effectiveness of a screening programme is controversial and depends mainly on the prevalence and adherence rates in the target population(3). Most prevalence studies have been based on individuals already attending healthcare centres, as genital samples are necessary to diagnose CT(4). The development of non-invasive self-collection sampling kits over the last 10 years has opened up opportunities for the screening of asymptomatic individuals and for the conduct of population-based surveys. Such surveys have rarely been carried out nation-wide. Existing studies include surveys conducted in 2000 in Great Britain(5) and Slovenia(6), in 1999-2002 in the USA(7), and in 2002 in the Netherlands(8). A large national population-based survey, investigating sexual behaviour in France (CSF survey), was conducted in 2006. This survey was the opportunity to carry out an epidemiological study estimating, for the first time, the prevalence of CT in the French general population and to investigate the feasibility of using a self-collection home sampling kit without requiring any face-to-face intervention. Data from the CSF survey were used to identify risk factors associated with CT infection.

\section{Methods}

\section{Sampling design}

The CSF(Contexte de la Sexualité en France) survey, was a national random population-based survey investigating sexual behaviour, carried out by telephone between October 2005 and March 2006, using two phase stratification sampling with unequal selection probabilities at each phase. The methodology is detailed elsewhere (9).Telephone numbers were selected randomly from the list of all 
non commercial telephone numbers. Only one eligible person per selected household was randomly selected to record age stratification criteria (first phase sample). Younger adults were given a higher probability of inclusion in the second phase sample. The participation rate in the CSF survey was $74,6, \%$. Overall, 12364 men and women aged 18 to 69 were administered a 40 minute standardized questionnaire.

At the end of the questionnaire, a third phase subsample was randomly selected among sexually experienced individuals aged between 18 and 44, using unequal inclusion probabilities according to age and risk behaviour stratification criteria: individuals aged 18 - $25(n=1955)$, and individuals aged between 26 - 44 having had at least two sexual partners or one new partner over the past year $(n=$ 979) were all included; 2023 individuals were randomly selected from the remaining individuals aged between 26 and 44 (fig 1). All individuals included in that subsample (4957) were eligible to be invited to participate in a CT home-sampling programme (NatChla study).

The NatChla study

A home testing kit (urine for male and auto-vaginal swab for women) was posted to participants. Participants then had to send their home sample by post to the Chlamydia Reference Laboratory (University Bordeaux 2). CT was tested for by PCR Cobas TaqMan, (Roche Diagnostics, Meylan, France). Participants who did not return the sample within one week were called to check that they received the kit. Two postal reminders were sent, 10 days and 20 days after the phone-call. A urine testing kit was sent to women who had not returned the swab after one month.

Each participant was directly informed of the results, through postal mail or by telephone from the laboratory, or by calling a free number using an anonymous code. All individuals with positive CT results were advised to undergo a medical examination, and received a letter addressed to a physician, recommending treatment for the patient and their partners. The participation rate was defined as the proportion of the eligible population who were tested, the acceptance rate as the proportion of the eligible population who received a kit, and the tested rate as the proportion of people receiving the kit who had the test performed.

The study was approved by the French Data Protection Authority (CNIL: Commission Nationale Informatiques et Libertés-CNIL). 


\section{Statistical analysis}

We calculated participation rates at each stage of selection for the NatChla study and estimated CT prevalence as a function of gender and age. Factors associated with a lower participation rate among eligible individuals, and factors associated with CT positivity among participants, were identified for each gender in univariate analyses.

The sampling design was intended to over select individuals who lived alone (first phase sample), who were younger and who had had multiple or new partners (second and third phase samples). Inverse probability-weighted estimates were used to obtain unbiased prevalences. These were also poststratified for gender, age, level of education, marital status and region to align the distribution of the sample with the distribution of the French population census data, as was done in the previous French national survey on sexual behaviour (10).

Logistic regressions were used to identify independent risk factors for participation and CT prevalence, including non-collinear factors showing a $p$ value $<0.25$, in univariate analyses.

Confidence intervals, statistical tests and logistic regressions were performed according to the complex sampling design, with the svy module of the STATA software Version 8.2 (StataCorps, Texas, USA).

Analyses were conducted for the whole study population and for individuals aged between 18 and 29 years who had the highest prevalence and might be targeted by systematic screening programmes.

Results

\section{Participation}

Out of the 4,957 individuals eligible to participate in NatChla, 3,780 (76\%) accepted to receive a home testing kit. The tested rate among those who accepted the kit increased after the reminders were sent out (fig 1). The proportion of individuals tested increased from $29 \%$ to $50 \%$ after a first telephone call, to $61 \%$ after the first reminder letter, and to $67 \%$ after second reminder letter (men: $65 \%$; women: $68 \%)$. An additional $3 \%$ of women were tested after receiving a third reminder letter with a urine sample kit, giving a final tested rate of $71 \%$ among women who accepted the kit.

In all, 2,580 of the 4,957 eligible individuals were tested, representing an overall participation rate of $52 \%$, lower for men (49\%) than for women $(54 \%$; $p<0.0001)$ (Tab 1). The overall participation rate was 
independently associated with sexual orientation (higher in individuals with same sex partners) and risk behaviour at the last intercourse (higher in people who did not use a condom with a new or casual partner). These associations were stronger in women than in men (Tab 1). In men, the participation rate was also independently associated with age (higher for men aged>29 years). Among women, the participation rate was also associated with education level (higher in those with a higher education level).

Out of 43 individuals (15 men, 28 women) with a positive CT test, information on follow-up was obtained for 38 of them (12 men; 26 women). All men and 24 out 26 women had been treated adequately and 27 persons (10 men; 17 women) informed their partners. Of the 27 partners informed, 22 (8 men's partner; 14 women's partner) were treated. Finally, 95\% of participants to NatChla with CT infection were treated, whereas $71 \%$ of their partners were informed and $58 \%$ treated.

\section{CT prevalence and risk factors}

The overall prevalence of CT among individuals aged between 18 and 44 was estimated at $1.4 \%$ [95 \% Cl: 0.8- 2.6] for men, and $1.6 \%$ [1.0 - 2.5] for women (Tab 2). CT prevalence was higher for the 18 to 29 year age-group (men: $2.5 \%$ [1.2 - 5.0]; women: $3.2 \%$ [2.0 - 5.3], than for the 30 to 44 year age-group (men: $0.7 \%$ [0.2 - 1.9]; women: 0.5\% [0.2 - 1.1]) (Tab 3).

For both men and women, univariate analysis showed that the prevalence was higher for individuals who did not cohabit with a partner, for individuals who had had multiple partners (2 or more) or a new sexual partner in the past year, and for those who had the last sexual intercourse with a casual or new partner (Tab 2). For men, increased prevalence was associated with living in the Paris area, not being born in France, and not using a condom during their last sexual intercourse. In women, increased prevalence was associated in addition with young age, a low level of education and with having had homo-bisexual relations over the past year.

In the multivariate logistic regression analysis of men aged between 18 and 44 years, factors remaining significantly associated with CT infection were having had the last sexual intercourse with a casual or new partner, and having had several partners (2 or more) in the past year. In women aged between 18 and 44 years, young age, a low level of education and a large number of sexual partners in the past year remained independently associated with CT (Tab 2). 
When restricting the multivariate analysis to individuals younger than 30 years additional variables were associated with CT infection: for men aged between 18 and 29, living in Paris area, and for women aged between 18 and 29, having had homo-bisexual relations over the past year, and having had the most recent sexual intercourse with a casual or new partner (Tab 3).

Discussion

NatChla is the first national study estimating CT prevalence from a randomly selected sample of the French general population. The NatChla study differs from other population-based surveys in that subjects are recruited by telephone. The rate of participation in NatChla (women: $54 \%$, men: $49 \%$ ) was between the one obtained using face-to-face contact (Great Britain National Survey of Sexual Attitudes and Lifestyles 2000 (Natsal): $71 \%(5)$, Slovenie: $83 \%(6)$ or in the US National Health and Nutrition Examination Survey (NHANES): 92\%(7)) and those obtained using methods based exclusively on posted items, including a mailed testing kit (UK Chlamydia Screening Studies (Class) project (11): $38 \%$ in women and $28 \%$ in men; Danish study(12): $38.6 \%$ in women and $26.8 \%$ in men; Dutch study(8):48\% in women and 33\% in men). Consistent with these studies, participation in NatChla was lower in men than in women

Natchla was part of the CSF survey which aimed to investigate sexual behaviour in France. Strengths and limits of the CSF survey were detailed by Bajos and al(9) in a study comparing the CSF survey with two previous national French surveys of sexual behaviour completed in 1970 and in 1992. In the CSF survey, people not reached by phone represented around $20 \%$ of the general population. They tended to be younger, more often single and less educated than respondents. Post-stratifications were performed to limit potential bias due to factors associated with non participation. Therefore, the subsample of persons tested for CT was post-stratified according to gender, age, education level and region (see Methods). However, the NatChla study lacked statistical power to estimate prevalence precisely in small subgroups, such as men and women with homo or bisexual relations, giving wide confidence intervals around estimates. 
The NatChla study was conducted to estimate the prevalence in sexually experienced individuals aged between 18 and 44 years from the French general population. Among them, prevalence rates were similar between men and women in these individuals: $1.4 \%$ [95 \% Cl: 0.8- 2.6] for men and 1.6 $\%[95 \% \mathrm{Cl}: 1.0$ - 2.5] for women (Tab 2).

Comparisons with prevalence previously reported by other countries are not simple, due to the use of different age groups to calculate rates. However, the age-specific Chlamydia prevalence was quite similar in Natchla and other national surveys in which it was estimated, with overlapping $95 \%$ confidence intervals. The prevalence in men aged between $18-24$ years was $2.4 \%$ [95 \% Cl: $1.0-5.7$ ] in NatChla, $2.7 \%$ [1.2- 5.8] in the British Natsal survey (5) and 4.1\% [ 2.2- 7.4] in Slovenia(6). In men aged between 20-29 years, the prevalence was 2.9\% [1.4 -5.7] in NatChla and 3.2 \% [2.4- 3.4] in NHANES(7). For women aged between 18-24 years, the prevalence was 3.6\% [1.9-6.8] in Natchla , $3.0 \%$ [1.7- 5.0] in the British Natsal survey and 4\% [2.2- 7.4] in Slovenia. In women aged between 2029 years, the prevalence was $3.2 \%$ [2.0 - 5.3] in Natchla and 1.9\% [1.0-3.4] in US NHANES. As expected, the prevalence in our survey was lower than in surveys conducted in French medical settings such as STI and family planning clinics, where prevalence rates of around 8 to $12 \%$ have been reported for subjects between 18 and 24 years old (13).

CT prevalence in our study decreased substantially in individuals older than 30 years old, for both genders, consistent with previous observations. In our study, CT prevalence in women aged 25-29 years did not differ much than the one found in women aged 18-24 years. High rates of prevalence in the 25-29 years age group is consistent with studies carried out in Belgium(14), Finland(15) and the Netherlands(8). Data from the French Chlamydia Surveillance System, based on a laboratory sentinel network (Renachla), showed that $20 \%$ of cases of CT infection in women were identified in women aged between 25 and 29 years(16). In most policies, screening of asymptomatic women is recommended before the age of 25 years. The consequence of this recommendation is that older women are frequently left out by screening strategies. As prevalence in women aged 25-29 years does not differ in France from women aged 18-24 years, screening may be considered for women until the age of 29 years. 
As expected, sexual behaviour — having had the most recent sexual intercourse with a new or casual partner or having had several sexual partners over the past few years - was strongly associated with risk of CT infection for both genders and for all age groups. In women aged between 18 and 29 years, having had both same and opposite sex partners in the last past year was also associated with CT infection.

The level of education was strongly associated with CT infection in women but not in men. CT prevalence was lowest in female graduates $(1 \%)$, whereas it was conversely very high among women with a low level of education, particularly among women aged between 18 and 29 (12.5\% [CI95\%:4.132.4])). A low prevalence rate was also reported in surveys on French university students (13). CT prevalence and education level were associated regardless of the sexual behaviour. Opportunities of asymptomatic screening are more frequent for women than men, mainly due to routine gynaecological and obstetrical follow up. However, there are no official recommendations for screening asymptomatic women in France. CT tests are performed in public health settings or when they are prescribed by private gynaecologists. In private settings, patients have to pay to have the test and are reimbursed later. This may limit access to screening for women on low incomes, especially if they have no symptoms, with then a higher proportion of undiagnosed infection. Information collected during the CSF interview on previous testing by CT supports this opinion. For the question "Have you already been tested for Chlamydia?", 3.3\% (Cl 95\%:2.9-4.9) of women with a low education level answered yes, whereas it was the case for $14.5 \%(\mathrm{Cl} 95 \%$ :12.8-16.3) of those with a high education level.. In men, the lack of association with educational level is likely due to the fact that systematic screening is rarely proposed in the routine care setting, CT being mainly diagnosed because of symptoms. Living in the Paris area was associated with CT infection in men aged between 18 and 29 years. Surveillance data in general practise show that urethritis which acts as an indicator of STIs in men, is more frequent in this region. Thus, men living in the Paris area seem to have a higher risk of contracting STIs than men living in other areas.

Our NatChla survey showed that self-collection of samples at home seems to be feasible in the French population. This method may allow high-risk subgroups to be reached more easily; indeed the participation rate observed was higher for individuals with recent risk factors of STIs. The participation rate was lower in men belonging to the youngest age group (39\%) and in women with a low level of 
education $(41 \%)$. The participation rates are still quite satisfying given that these individuals have more limited access to the traditional healthcare system and are generally more difficult to reach. The NCSP (National Chlamydia Screening Programme), implemented in England since 2003, has demonstrated that a wide variety of strategies must be used to reach this population for screening(17). Web-based methods and offering to send a test kit have been recently introduced to screen target populations in this programme and in others countries $(18 ; 19)$.

In a previous study conducted in Sweden using an Internet-based method, the authors concluded that this could be a valuable additional tool to use in opportunistic screening to reach people who do not attend healthcare facilities(20). These methods may help to reduce health costs, as kits are only sent to those who request them, and physician intervention is limited to people who test positive.

Previous sentinel surveillance studies of sexually transmitted infections and behavioural surveys have shown increases in STIs(21) and sexual risk behaviour in France and in other European countries (22). Estimating the prevalence of CT in the general population though the NatChla survey assists us to evaluate the number of persons infected in France at the time of the study. Thus, we estimated that between 71,000 and 203,000 women and between 47,000 and 197,000 men, aged 18-29 years, were infected in France in 2006. The absence of a national screening programme in France, partly due to there being no evidence of cost-effectiveness and feasibility of such a programme, could cause CT infection to spread, subsequently increasing the number of cases of infertility in the population.

It is the first time that estimates of national prevalence, overall and in various subgroups, are available to estimate costs and sensitivities of different screening strategies in general population. Systematic screening in STI clinics and in HIV testing sites is the strategy currently supported by the French government. The next step will be to promote screening in other high risk sub-populations who does not attend such settings. Further studies including economic assessments are necessary to evaluate various approaches, such as internet based proposal, to reach these high risk sub- populations.

\section{Acknowledgments}

We thank interviewers of the CSF survey for their contribution to this substudy and for achieving a good acceptance rate to the NatChla study. 
We thank Hélène Haguy who was in charge of sending the kits, Catherine Sale who was in charge of the follow up of the participation to the test and Danièle David who was in charge of the organisation of the pilot study.

Members of the scientific committee of NatChla who are not authors of this paper for their advices :

Annie Velter, Judith Cytrynowicz

\section{Funding}

The Natchla survey was funded by the Agence Nationale de Recherche sur le Sida et les hépatites (ANRS) and the French Institute for Public Health Surveillance (Institut de veille sanitaire - InVS). The Institut de veille sanitaire is funded by the French Ministry of Health. The National Reference Centre is funded by a grant from the Institut de veille sanitaire.

Competing Interests: None declared

Copyright licence statement

The Corresponding Author has the right to grant on behalf of all authors and does grant on behalf of all authors, an exclusive licence (or non-exclusive for government employees) on a worldwide basis to the BMJ Publishing Group Ltd and its Licensees to permit this article (if accepted) to be published in Sexually Transmitted Infections and any other BMJPGL products to exploit all subsidiary rights, as set out in our licence.

\section{Key Messages:}

Prevalence of Chlamydia trachomatis (CT) infection in the general population in France is similar to the one found in other European countries.

The highest rates are reported in persons aged 18-29 years, or those having had multiple or new partners in the last year.

Women with a low educational level are at higher risk of undiagnosed CT infection. 
Home-sampling is well accepted by the French population and useful to reach members of the population with limited access to traditional health care.

\section{$\underline{\text { Contributors }}$}

V Goulet was responsible and supervised the NatChla study, performed statistical analysis and was the main writer of the paper

B de Barbeyrac, was in charge of the laboratory testing and giving medical advice for infected patients and, with the assistance of S. Raherison for technical coordination, participated in the drafting of the paper

C. Semaille and M Prudhomme and participated in the conception of the design of the NatChla study and in the drafting of the paper

J Warszawski, participated in the conception of the CSF study, especially sampling design, was coresponsible of the NatChla study, participated in the statistical analysis and in writing the paper CSF team : Nathalie Bajos, M. Bozon, N. Beltzer, A. Andro, M. Ferrand, V. Goulet, A. Laporte, Ch. Le Van, H. Leridon, Sh. Levinson, N. Razafindratsima, L.Toulemon, J. Warszawski were in charge of the implementation and the analysis of the CSF (Contexte de la Sexualité en France) survey

Final draft was submitted to all authors for comments. 
Reference List

(1) Paavonen J, Eggert-Kruse W. Chlamydia trachomatis: impact on human reproduction. Hum Reprod Update 1999 Sep;5(5):433-47.

(2) Low N. Screening programmes for chlamydial infection: when will we ever learn? BMJ 2007 Apr 7;334(7596):725-8.

(3) Roberts TE, Robinson S, Barton P, Bryan S, Low N. Screening for Chlamydia trachomatis: a systematic review of the economic evaluations and modelling. Sex Transm Infect 2006 Jun;82(3):193-200.

(4) Adams EJ, Charlett A, Edmunds WJ, Hughes G. Chlamydia trachomatis in the United Kingdom: a systematic review and analysis of prevalence studies. Sex Transm Infect 2004 Oct;80(5):354-62.

(5) Fenton KA, Korovessis C, Johnson AM, McCadden A, McManus S, Wellings K, et al. Sexual behaviour in Britain: reported sexually transmitted infections and prevalent genital Chlamydia trachomatis infection. Lancet 2001 Dec 1;358(9296):1851-4.

(6) Klavs I, Rodrigues LC, Wellings K, Kese D, Hayes R. Prevalence of genital Chlamydia trachomatis infection in the general population of Slovenia: serious gaps in control. Sex Transm Infect 2004 Apr;80(2):121-3.

(7) Datta SD, Sternberg M, Johnson RE, Berman S, Papp JR, McQuillan G, et al. Gonorrhea and chlamydia in the United States among persons 14 to 39 years of age, 1999 to 2002. Ann Intern Med 2007 Jul 17;147(2):89-96.

(8) van Bergen J., Gotz HM, Richardus JH, Hoebe CJ, Broer J, Coenen AJ. Prevalence of urogenital Chlamydia trachomatis increases significantly with level of urbanisation and suggests targeted screening approaches: results from the first national population based study in the Netherlands. Sex Transm Infect 2005 Feb;81(1):17-23. 
(9) Bajos N, Bozon M, Beltzer N, Laborde C, Wellings K, CSF Group. Changes in sexual behaviours: from secular trends to public health policies. AIDS 2009.

(10) Warszawski J, Messiah A, Lellouch J, Meyer L, Deville JC. Estimating means and percentages in a complex sampling survey: application to a French national survey on sexual behaviour (ACSF). Analyse des Comportements Sexuels en France. Stat Med 1997 Feb 28;16(4):397-423.

(11) Macleod J, Salisbury C, Low N, McCarthy A, Sterne JA, Holloway A, et al. Coverage and uptake of systematic postal screening for genital Chlamydia trachomatis and prevalence of infection in the United Kingdom general population: cross sectional study. BMJ 2005 Apr $23 ; 330(7497): 940$.

(12) Andersen B, Olesen F, Moller JK, Ostergaard L. Population-based strategies for outreach screening of urogenital Chlamydia trachomatis infections: a randomized, controlled trial. $J$ Infect Dis 2002 Jan 15;185(2):252-8.

(13) Special issue - Chlamydia trachomatis: Prevalence studies in health facilities providing preventive medicine. Bull Epidemiol Hebd 2006 [37-38], 275-289.

http://www.invs.sante.fr/beh/2004/40_41/beh_40_41_2004.pdf (accessed 4 Jan 2010)

(14) Verhoeven V, Avonts D, Meheus A, Goossens H, leven M, Chapelle S, et al. Chlamydial infection: an accurate model for opportunistic screening in general practice. Sex Transm Infect 2003 Aug;79(4):313-7.

(15) Lyytikainen E, Kaasila M, Hiltunen-Back E, Lehtinen M, Tasanen K, Surcel HM, et al. A discrepancy of Chlamydia trachomatis incidence and prevalence trends in Finland 1983-2003. BMC Infect Dis 2008;8:169.

(16) Goulet V, Laurent E. Les infections à Chlamydia trachomatis en france en 2002. Bull Epidemiol Hebd 2004;(40-41):194-5.

http://www.invs.sante.fr/beh/2004/40_41/beh_40_41_2004.pdf (accessed 4 Jan 2010) 
(17) Simms I, Talebi A, Rhia J, Horner P, French RS, Sarah R, et al. The English National Chlamydia Screening Programme: Variations in Positivity in 2007/2008. Sex Transm Dis 2009 May 18.

(18) Lippman SA, Jones HE, Luppi CG, Pinho AA, Veras MA, van de Wijgert JH. Home-based selfsampling and self-testing for sexually transmitted infections: acceptable and feasible alternatives to provider-based screening in low-income women in Sao Paulo, Brazil. Sex Transm Dis 2007 Jul;34(7):421-8.

(19) Gaydos CA, Barnes M, Aumakhan B, Quinn N, Agreda P, Whittle P, et al. Can E-Technology Through the Internet be Used as a New Tool to Address the Chlamydia trachomatis Epidemic by Home Sampling and Vaginal Swabs? Sex Transm Dis 2009 Jun 17.

(20) Novak DP, Karlsson RB. Simplifying chlamydia testing: an innovative Chlamydia trachomatis testing approach using the internet and a home sampling strategy: population based study. Sex Transm Infect 2006 Apr;82(2):142-7.

(21) Herida M, Michel A, Goulet V, Janier M, Sednaoui P, Dupin N, et al. [Epidemiology of sexually transmitted infections in France]. Med Mal Infect 2005 May;35(5):281-9.

(22) Annual Epidemiological Report on Communicable Diseases in Europe 2008. http://ecdc.europa.eu/en/publications/Publications/0812_SUR_Annual_Epidemiological_Repor t_2008.pdf. 
Table 1: Characteristics of participants in the NatChla survey: participation rate and factors associated with participation

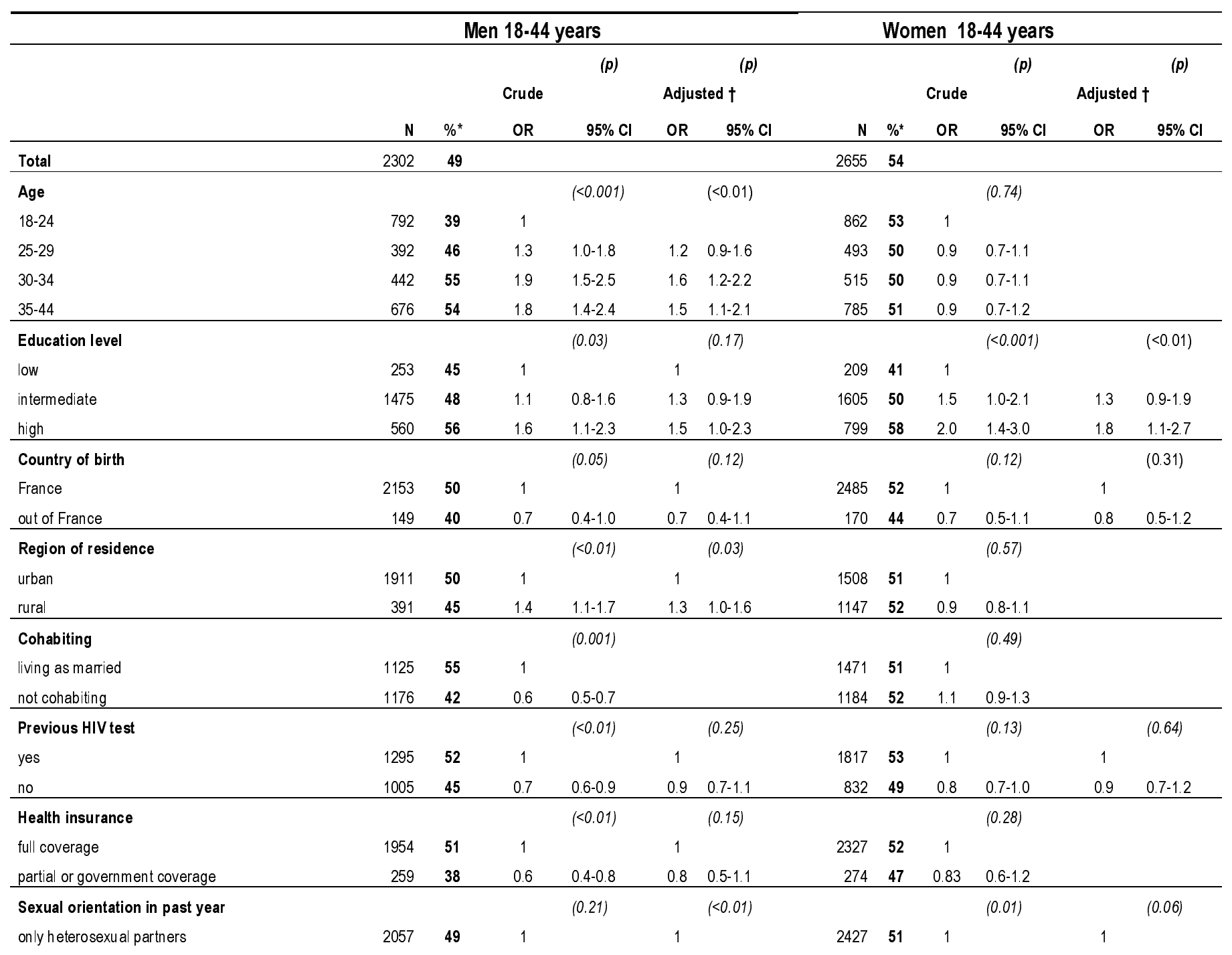




\begin{tabular}{|c|c|c|c|c|c|c|c|c|c|c|c|c|}
\hline bisexual partners & 110 & 48 & 1.0 & $0.6-1.6$ & 1.0 & $0.6-1.8$ & 147 & 68 & 2.0 & $1.3-3.2$ & 1.9 & $1.1-2.9$ \\
\hline only same sex partners & 28 & 80 & 4.1 & $1.7-10.1$ & 4.9 & $1.9-12.9$ & 3 & 49 & 0.9 & $0.1-10.4$ & 0.8 & $0.1-7.8$ \\
\hline Number of sexual partners in past year & & & & $(<0.01)$ & & (0.68) & & & & $(<0.01)$ & & $(0.55)$ \\
\hline $0-1$ & 1625 & 52 & 1 & & 1 & & 2084 & 51 & 1 & & 1 & \\
\hline 2 & 264 & 40 & 0.6 & $0.5-0.8$ & 0.9 & $0.6-1.2$ & 339 & 58 & 1.4 & $1.0-1.8$ & 1.0 & $0.7-1.5$ \\
\hline$>2$ & 335 & 44 & 0.7 & $0.5-1.0$ & 1,0 & $0.7-1.4$ & 182 & 62 & 1.6 & $1.1-2.4$ & 1.3 & 0.8-2.1 \\
\hline New partner in the past year & & & & $(<0.01)$ & & (0.34) & & & & $(<0.01)$ & & $(0.46)$ \\
\hline 0 & 1240 & 52 & 1 & & 1 & & 1709 & 50 & 1 & & 1 & \\
\hline$\geq 1$ & 882 & 42 & 0.7 & $0.6-0.8$ & 0.9 & $0.6-1.2$ & 820 & 58 & 1.4 & $1.1-1.7$ & 1.1 & $0.8-1.5$ \\
\hline Partner at last intercourse & & & & $(0.02)$ & & & & & & $(0.02)$ & & \\
\hline cohabiting or principal partner & 1694 & 51 & 1 & & & & 2227 & 51 & 1 & & & \\
\hline casual & 89 & 35 & 0.5 & $0.3-0.9$ & & & 72 & 63 & 1.6 & $0.9-2.9$ & & \\
\hline new partner $<3$ months & 393 & 45 & 0.8 & $0.6-1.0$ & & & 252 & 61 & 1.5 & $1.1-2.1$ & & \\
\hline Condom at last intercourse & & & & $(<0.001)$ & & $(0.09)$ & & & & $(<0.01)$ & & $(<0.01)$ \\
\hline condom used with regular partner & 417 & 40 & 1 & & 1 & & 401 & 47 & 1 & & 1 & \\
\hline condom used with casual or new partner (<3months) & 349 & 41 & 1.1 & $0.8-1.5$ & 1.2 & $0.8-1.8$ & 212 & 55 & 1.4 & $0.9-2.1$ & 1.3 & $0.8-2.0$ \\
\hline no condom used, regular partner & 1250 & 54 & 1.8 & $1.3-2.3$ & 1.4 & $1.0-1.9$ & 1799 & 52 & 1.2 & $0.9-1.6$ & 1.3 & $1.0-1.7$ \\
\hline no condom used, casual or new partner (<3months) & 131 & 48 & 1.4 & $0.9-2.3$ & 1.7 & $1.0-2.8$ & 112 & 73 & 3.1 & $1.7-5.7$ & 3.0 & $1.6-5.5$ \\
\hline STI in the last 5 years & & & & (0.31) & & & & & & $(0.02)$ & & $(0.22)$ \\
\hline yes & 2238 & 57 & 1 & & & & 96 & 67 & 1 & & 1 & \\
\hline no & 61 & 49 & 0.7 & $0.4-1.4$ & & & 2557 & 51 & 0.5 & $0.3-0.9$ & 0.69 & $0.4-1.3$ \\
\hline
\end{tabular}

* participation rate was weighted to take in account unequal selection probability and was post-stratified for sex, age, level of education, marital status and region of residence

† OR adjusted were presented for all variables included in logistic models, selected if $p<0.25$ and non collinear in univariate analysis 
Table 2 Prevalence and risk factors associated with Chlamydia trachomatis infection in the French population for individuals aged between 18 and 44 (NatChla study, CSF survey)

\begin{tabular}{|c|c|c|c|c|c|c|c|c|c|c|c|c|c|c|c|c|}
\hline & \multicolumn{8}{|c|}{ Men $18-44$ years } & \multicolumn{8}{|c|}{ Women $18-44$ years } \\
\hline & \multirow[b]{3}{*}{$\mathbf{N}$} & \multirow[b]{3}{*}{$\mathrm{n}$} & \multirow{2}{*}{\multicolumn{2}{|c|}{ Prevalence }} & \multirow{3}{*}{$\begin{array}{c}\text { Crude } \\
\text { OR }\end{array}$} & \multirow[t]{2}{*}{ (p) } & \multicolumn{2}{|r|}{ (p) } & \multirow[b]{3}{*}{$\mathrm{N}$} & \multirow[b]{3}{*}{$\mathbf{n}$} & \multirow{2}{*}{\multicolumn{2}{|c|}{ Prevalence }} & \multirow{3}{*}{$\begin{array}{c}\text { Crude } \\
\text { OR }\end{array}$} & \multicolumn{2}{|l|}{ (p) } & (p) \\
\hline & & & & & & & Adjust & & & & & & & & Adjust & \\
\hline & & & $\%^{*}$ & $95 \% \mathrm{Cl}$ & & $95 \% \mathrm{Cl}$ & ORt & $\begin{array}{c}95 \% \\
\mathrm{Cl}\end{array}$ & & & $\%^{*}$ & $95 \% \mathrm{Cl}$ & & $95 \% \mathrm{Cl}$ & $\mathrm{OR} \dagger$ & $95 \% \mathrm{Cl}$ \\
\hline Total & 1135 & 15 & 1.4 & $0.8-2.6$ & & & & & 1445 & 28 & 1.6 & $1.0-2.5$ & & & & \\
\hline Age & & & & & & $(0.28)$ & & & & & & & & $(<0.001)$ & & $(0.05)$ \\
\hline $18-24$ & 322 & 6 & 2.4 & $1.0-5.7$ & 1 & & & & 106 & 4 & 3.6 & $1.9-6.8$ & 1 & & 1 & \\
\hline $25-29$ & 186 & 4 & 2.7 & $0.8-8.0$ & 1.1 & $0.3-4.8$ & & & 361 & 11 & 2.7 & $1.2-6.1$ & 0.7 & $0.2-2.1$ & 1.1 & $0.3-3.7$ \\
\hline $30-34$ & 255 & 3 & 1.1 & $0.3-3.7$ & 0.4 & $0.1-2.1$ & & & 140 & 5 & 0.6 & $0.1-2.7$ & 0.2 & $0.0-0.8$ & 0.2 & $0.0-1.7$ \\
\hline $35-44$ & 372 & 2 & 0.5 & $0.1-2.6$ & 0.2 & $0.0-1.4$ & & & 130 & 2 & 0.4 & $0.1-1.2$ & 0.1 & $0.0-0.4$ & 0.2 & $0.0-0.8$ \\
\hline Education level & & & & & & $(0.87)$ & & & & & & & & $(0.04)$ & & $(0.04)$ \\
\hline high & 319 & 3 & 1.0 & $0.2-4.4$ & 1 & & & & 498 & 4 & 0.5 & $0.2-1.4$ & 1 & & 1 & \\
\hline intermediate & 698 & 10 & 1.6 & $0.8-3.1$ & 1.6 & $0.3-8.4$ & & & 832 & 21 & 1.7 & $1.1-2.8$ & 3.6 & $1.1-11.9$ & 3.2 & $0.8-12.5$ \\
\hline Region of residence & & & & & & $(0.03)$ & & $(0.15)$ & & & & & & $(0.07)$ & & $(0.09)$ \\
\hline Outside Paris area & 951 & 8 & 1 & $0.5-2.1$ & 1 & & 1 & & 629 & 12 & 1.3 & $0.7-2.5$ & 1 & & 1 & \\
\hline Paris area & 184 & 7 & 3.5 & $1.4-8.5$ & 3.5 & $1.1-11.8$ & 2.5 & $0.7-8.5$ & 816 & 16 & 2.9 & $1.4-5.9$ & 2.3 & $0.9-5.9$ & 2.2 & $0.9-5.6$ \\
\hline Country of birth & & & & & & $(0.04)$ & & & & & & & & $(0.45)$ & & \\
\hline France & 1076 & 12 & 1.1 & & 1 & & & & 1364 & 25 & 1.5 & $0.9-2.4$ & 1 & & & \\
\hline out of France & 59 & 3 & 4.6 & & 4.2 & $1.0-17.7$ & & & 81 & 3 & 2.7 & $0.8-9.1$ & 1.9 & $0.5-7.4$ & & \\
\hline Cohabiting & & & & & & $(<0.01)$ & & & & & & & & $(<0.01)$ & & \\
\hline living in couple & 612 & 4 & 0.5 & $0.2-1.4$ & 1 & & & & 789 & 9 & 0.8 & $0.4-1.7$ & 1 & & & \\
\hline not cohabiting & 523 & 11 & 2.6 & $1.3-5.0$ & 5.6 & $1.6-20.4$ & & & 656 & 19 & 2.9 & $1.7-4.9$ & 3.7 & $1.4-9.6$ & & \\
\hline Health insurance & & & & & & $(0.25)$ & & & & & & & & $(0.74)$ & & \\
\hline full coverage & 990 & 14 & 1.5 & $0.8-2.7$ & & & & & 1275 & 22 & 1.6 & $0.9-2.6$ & 1 & & & \\
\hline partial or government coverage & 103 & 0 & 0 & & - & & & & 140 & 5 & 2.0 & $0.6-6.4$ & 1.3 & $0.3-4.8$ & & \\
\hline
\end{tabular}




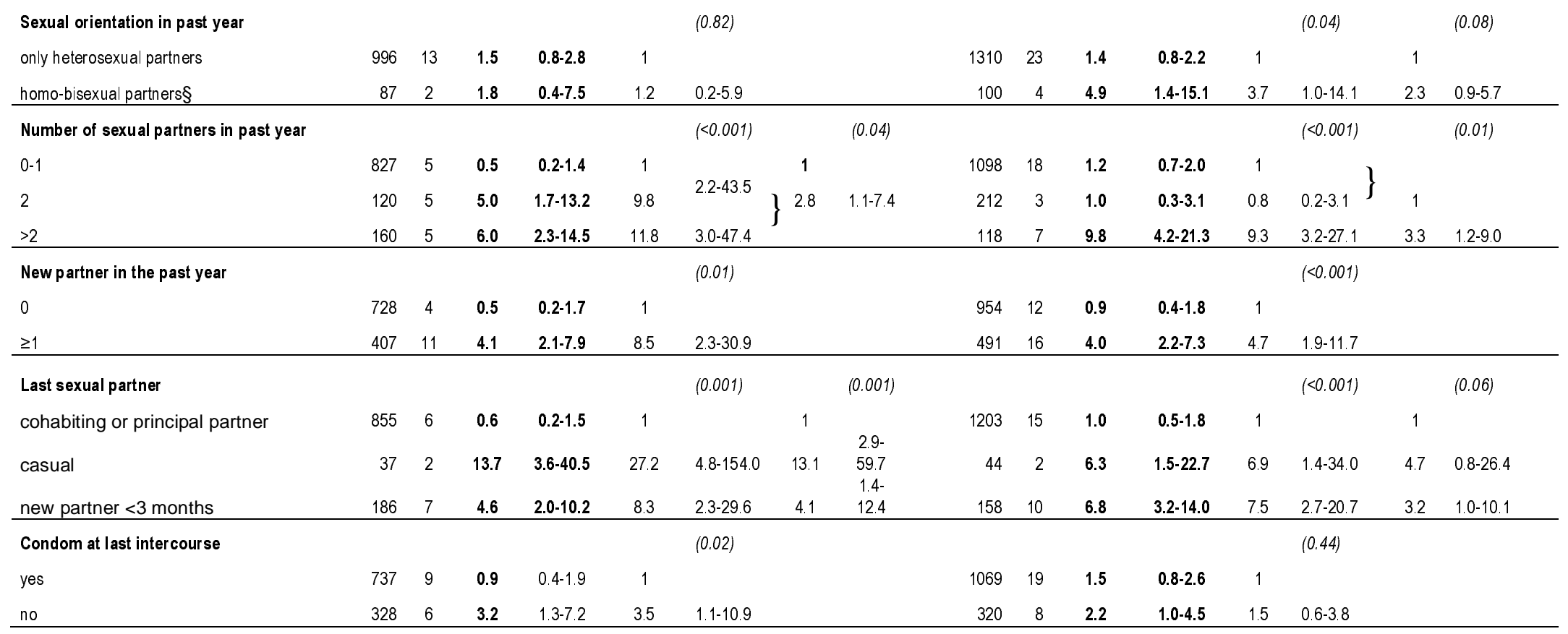

* prevalence weighted to take into account unequal selection probability and post-stratified for sex, age, level of education, marital status and region of residence

† OR adjusted were presented for all variables included in logistic models, selected if $p<0.25$ and non collinear in univariate analysis

$\ddagger$ variable recoded in 2 classes, combining classes with similar prevalence

§homo-bisexual partners : all 4 women infected with CT were bisexual, 1 out 2 men infected with CT was bisexual 
Table 3 Prevalence and risk factors associated with Chlamydia trachomatis infection in the French population for individuals aged between 18 and 29 (NatChla study, CSF survey)

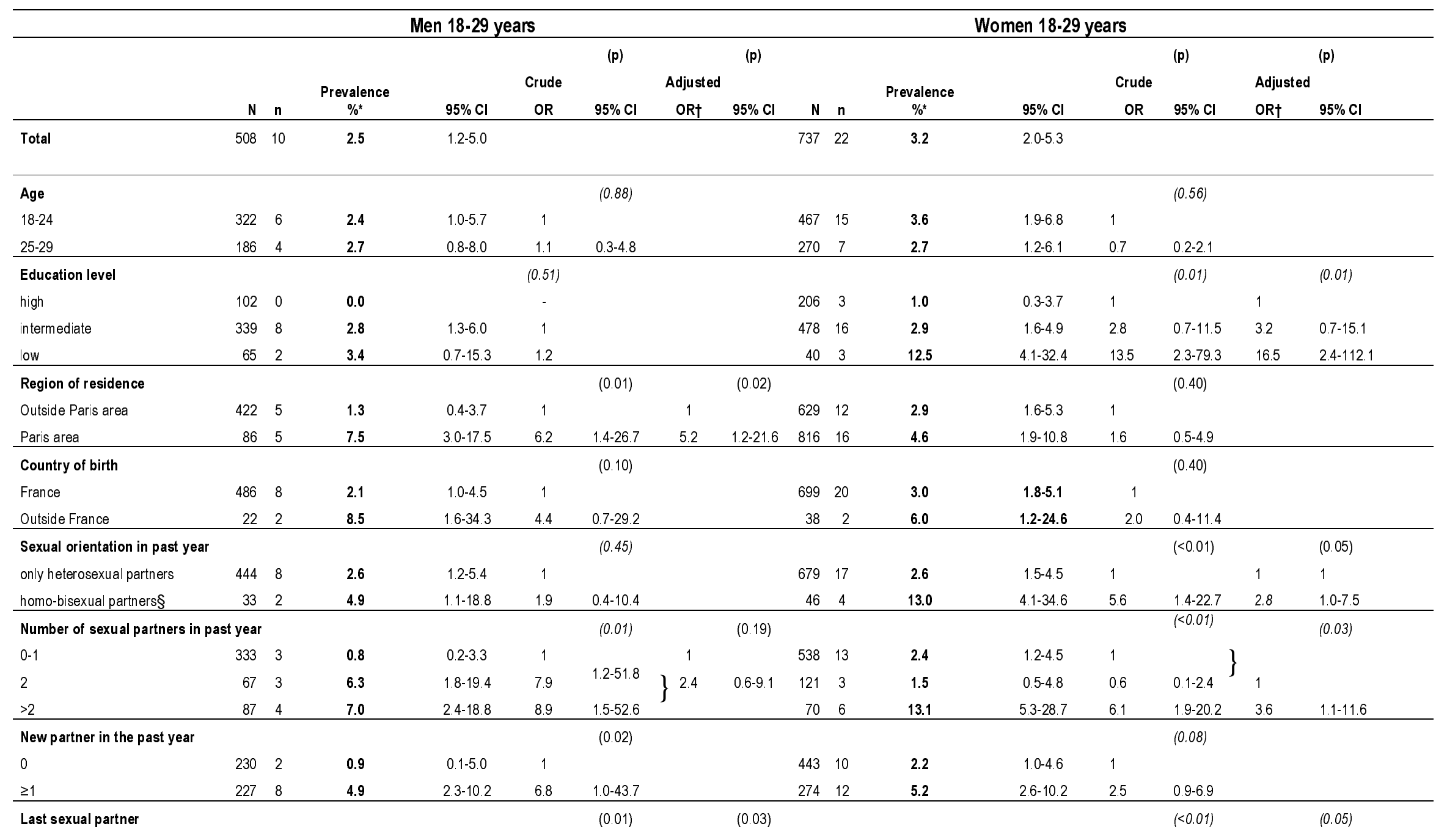




\begin{tabular}{|c|c|c|c|c|c|c|c|c|c|c|c|c|c|c|c|c|}
\hline cohabiting or principal partner & 333 & 3 & 0.8 & $0.2-3.4$ & 1 & & 1 & & 596 & 11 & 2.0 & $1.0-4.2$ & 1 & & 1 & \\
\hline casual & 23 & 1 & 11.1 & $1.6-48.7$ & 14.7 & $1.2-174.0$ & 12.7 & $1.4-116.4$ & 24 & 2 & 11.9 & $2.9-37.6$ & 6.5 & $1.2-34.5$ & 7.0 & $1.2-42.0$ \\
\hline new partner $<3$ months & 119 & 6 & 6.1 & $2.6-13.8$ & 7.7 & $1.4-41.2$ & 4.6 & $1.1-19.5$ & 103 & 8 & 8.4 & $3.6-18.4$ & 4.4 & $1.4-14.2$ & 2.6 & $0.8-8.2$ \\
\hline Condom at last intercourse & & & & & & $(0.20)$ & & & & & & & & (0.64) & & \\
\hline yes & 193 & 5 & 4.1 & $1.6-10.1$ & 1 & & & & 194 & 6 & 2.7 & $1.2-6.3$ & 1 & & & \\
\hline no & 276 & 5 & 1.7 & $0.7-4.5$ & 0.41 & $0.6-9.7$ & & & 517 & 15 & 3.5 & $1.9-6.4$ & 0.8 & $0.3-2.3$ & & \\
\hline
\end{tabular}

* prevalence weighted to take into account unequal selection probability and post-stratified for sex, age, level of education, marital status and region of residence

† OR adjusted were presented for all variables included in logistic models, selected if $p<0.25$ and non collinear in univariate analysis

$¥$ variable recoded in 2 classes, combining classes with similar prevalence

§homo-bisexual partners : all 4 women infected with CT were bisexual , 1 out 2 men infected with CT was bisexual 


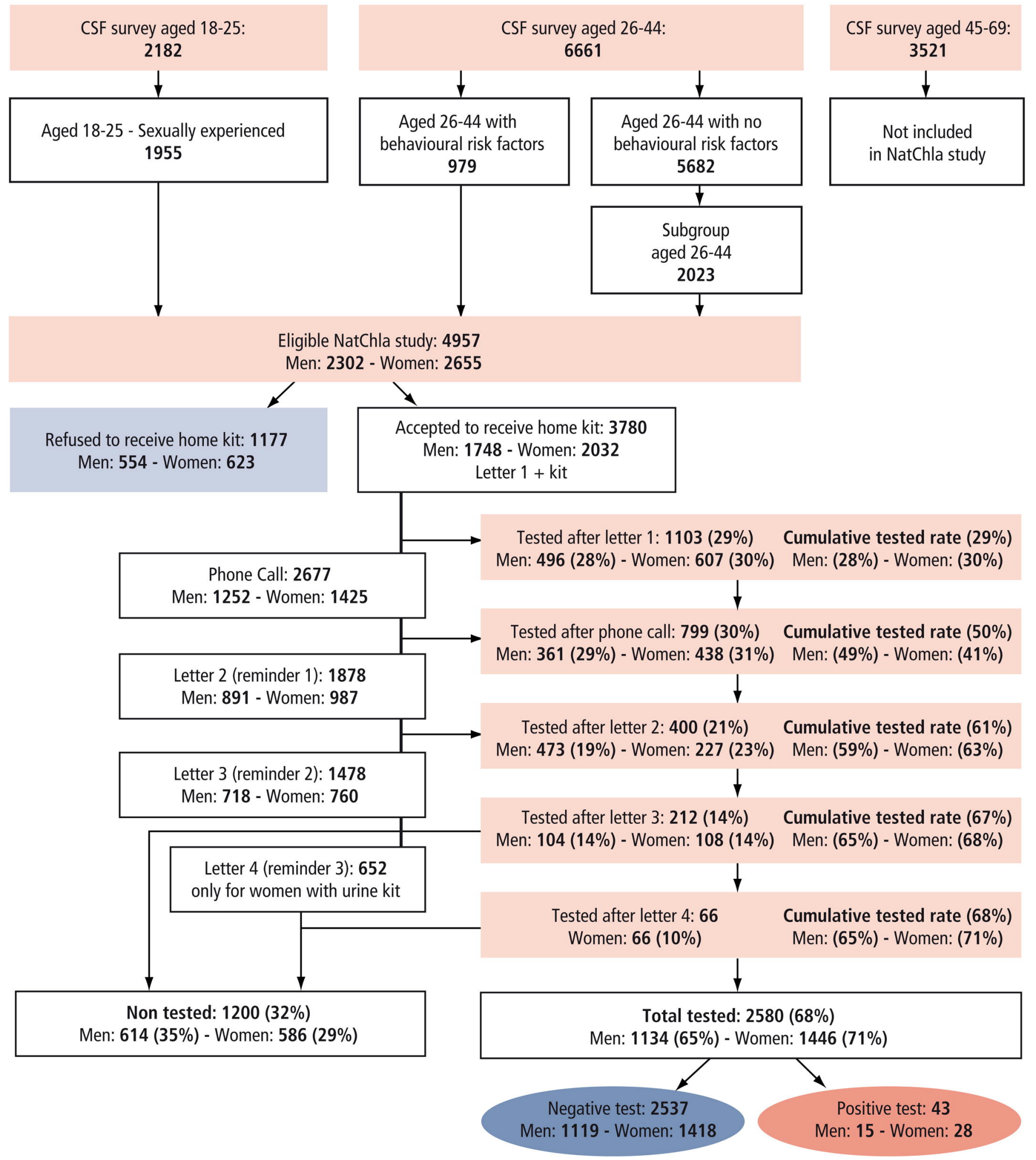

